\title{
Seroprevalence of HIV, Hepatitis B and C Viruses Infections among Candidates for Cataract Surgery
}

\author{
Angue Tatiana Harly Mba Aki1,2* (D), Emmanuel Anyunzoghe3, Patrice Emery Itoudi Bignoumba4,

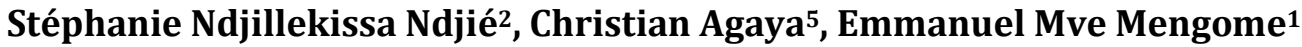 \\ ${ }^{1}$ Department of Ophthalmology, Faculty of Medicine, USS, Libreville, Gabon \\ ${ }^{2} \mathrm{CHU}$ Owendo, Libreville, Gabon \\ ${ }^{3}$ Department of Epidemiology, Biostatistics and Medical Informatics, Faculty of Medicine, USS, Libreville, Gabon \\ ${ }^{4}$ Department of Hepato-Gastroenterology, Libreville, Gabon \\ ${ }^{5}$ National Program to Fight Blindness, Libreville, Gabon \\ Email: *mbatati4@yahoo.fr
}

How to cite this paper: Mba Aki, A.T.H., Anyunzoghe, E., Itoudi Bignoumba, P.E., Ndjillekissa Ndjié, S., Agaya, C. and Mve Mengome, E. (2019) Seroprevalence of HIV, Hepatitis B and C Viruses Infections among Candidates for Cataract Surgery. Open Journal of Ophthalmology, 9, 47-53. https://doi.org/10.4236/ojoph.2019.92006

Received: January 19, 2019

Accepted: March 22, 2019

Published: March 25, 2019

Copyright $\odot 2019$ by author(s) and Scientific Research Publishing Inc. This work is licensed under the Creative Commons Attribution International License (CC BY 4.0).

http://creativecommons.org/licenses/by/4.0/

\begin{abstract}
Introduction: The safety issue of mass surgeries in areas of higher endemicity for HIV, HBV and HCV is raised. Objective: The objective was to determine the frequency of HIV, HBV and HCV among people undergoing a cataract surgery during humanitarian surgical mission. Patients and Method: This prospective study was conducted at CHU Owendo from April to September 2018. Cataract-operated patients were the targeted population. Rapid screening tests were used for diagnosis. Parameters such as age, sex, frequency of HIV, HBV, HCV, and co-infections were analyzed. Sero-positivity was correlated with age and sex. A total of 1403 patients were included. Statistical analysis was performed with EPI Info 7.2 (Chi ${ }^{2}$ uncorrected, Mann-Whitnney and Wilcoxon, $\mathrm{p}<0.05)$. Results: Patients mean age was $66.3 \pm 11.6$ years; $42.1 \%$ of them were male. With $18.0 \%$ of the study population, HIV-positive people had mean age of $78.4 \pm 9.3$ years, compared to $61.2 \pm 10.1$ years for sero-negative $(\mathrm{p}<0.001)$. HIV prevalence was $4.6 \%(95 \% \mathrm{CI}=[3.7-5.9]), \mathrm{HBV}$ was $2.9 \%(95 \% \mathrm{CI}=[2.1-3.9])$, and $\mathrm{HCV}$ was $11.8 \%(95 \% \mathrm{CI}=[10.2-$ 13.6]). Co-infections occurred in $1.2 \%(95 \% \mathrm{CI}=[0.8-1.9])$ of patients undergoing surgery. Conclusion: This study showed high prevalence of HIV, $\mathrm{HBV}$ and $\mathrm{HCV}$ among patients undergoing cataract surgery with predominance for HCV. Viral co-infections prevalence was also significant.
\end{abstract}

\section{Keywords}

HIV, HCV, HBV, Surgery, Cataract, Libreville 


\section{Introduction}

According to WHO, cataract is the leading cause of blindness worldwide with more than 18 million cases [1]. Treatment of cataract is the most popular surgery around the world [2]. In order to reduce prevalence of cataract-related blindness and meet Vision 2020 objectives, many African countries are increasingly using humanitarian surgical missions. This practice provides eye care to a large number of low-resource populations. However, there is a safety issue regarding such surgical interventions in areas of high endemicity for HIV infections, viral hepatitis B (HBV) and C (HCV). On a global scale, the number of people infected by HBV in 2015 was estimated at 257 million and 71 million for HCV [3].

HIV affects more than 36.7 million people. These three viral transmissible infections mainly affect Africa [4] [5]. Their higher endemicities have motivated a number of initiatives. Indeed, medical teams were led to include serological tests for the 3 viral infections in the pre-operative checkup of eye surgeries [6] [7] [8] [9]. A viral particle of HBV, HCV and HIV in the aqueous humor was also reported [10] [11] [12]. Experimental studies have confirmed transmission risks of viral infections during surgery, especially through phacoemulsification technique [13]. Phacoemulsification technique and Small incision cataract surgery (SICS) use very sharp instruments at different stages of cataract surgery, exposing to risks of injury and contamination.

Lack of consensus on the issue of pre-operative screening regarding HIV, $\mathrm{HBV}$, and C prior to cataract surgery has motivated the present study. The aim was to determine the seroprevalence of these infections among patients undergoing surgery during humanitarian surgical mission.

\section{Material and Methods}

This prospective study was conducted at CHU Owendo from April to September 2018 during the humanitarian medical-surgical mission "Vision for all". The target population was cataract-operated patients. Recruitment was carried out in ophthalmology units where pre-operative checkups for HIV, HBV and HCV serology were prescribed. Surgical procedure was free of charge; patients had to bear the serology costs. Laboratory screening tests were serological rapid tests interpreted according to $\mathrm{WHO}$ guidelines [14] and results were validated by microbiologists. Any HIV positive serology in rapid tests required diagnostic confirmation through Elisa technique. SICS surgery was performed to patients with positive serology in at least one virological test. Seronegative patients to HIV, $\mathrm{HBV}$ and $\mathrm{HCV}$ were treated with phacoemulsification technique.

As per the daily schedule, surgical procedures started with seronegative patients, then patients who didn't have any serological test, and ended with seropositive patients. To maintain sterility, surgical procedures were carried out in an operating room exclusively dedicated to ophthalmology and disinfected at the end of each operating day. Surgical micro-instruments were sterilized in an au- 
toclave after each procedure. Surgical drapes were single-use and gloves were changed between each patient. A total of 1918 eyes from 1634 patients received cataract surgery during the humanitarian medical Mission "Vision for All". Among them, 1403 patients, with serological records, were included in this study and 231 not included because of not having a serological test. Studied parameters included age, sex, frequency of single HIV, HBV or HCV infections, and co-infections.

Seropositivity was correlated to age and gender. Bilateral cataract surgery during the study period was recorded as one single operation to determine the different parameters. This work complied with the Helsinki Declaration on research ethics involving living beings. Informed consent was obtained from the participants. Individuals whose viral positive status was discovered at the time of the study were referred to a specialist. Psychological care was provided in case of HIV positive serology. Statistical analysis was performed with EPI Info 7.2 software. Uncorrected $\mathrm{Chi}^{2}$ test was used to compare frequencies, whereas continuous variables were expressed by means and compared using the Mann-Whitney and Wilcoxon test $(\mathrm{p}<0.05)$.

\section{Results}

\subsection{Study Population}

The study population mean age was $66.3( \pm 11.6)$. Sex-ratio was 0.73 with female predominance (58\%). Modal age class was 60 - 70-years old (42\%) for male and 70 - 80 (37\%) for female (Table 1).

\subsection{Viral Seroprevalence}

Viral seroprevalence rate was $18.0 \%$ with mean age of $78.4 \pm 9.3$ years, compared to $61.2 \pm 10.1$ for seronegative participants $\left(\mathrm{p}<10^{-3}\right)$ (Table 2).

\subsection{Viral Seroprevalence versus Age}

HIV prevalence among patients undergoing surgery was 4.6\% (95\% CI $=[3.7$ 5.9]) with mean age of $71.9 \pm 9.5$ years compared to $66.4 \pm 11.4$ years for HIV seronegative people $(\mathrm{p}=0.002)$. HIV seropositive modal age class was $60-70$ years (58\%) (Table 2).

HBV prevalence was $2.9 \%(95 \% \mathrm{CI}=[2.1-3.9])$ with mean age of $73.7 \pm 14.5$ years compared to $66.5 \pm 11.2$ years for HBV seronegative people $(\mathrm{p}=0.0154)$. HBV seropositive modal age class was 60 - 70 years (63\%) (Table 2).

Table 1. Study population.

\begin{tabular}{cccccc}
\hline Variable & $\mathbf{n}$ & $\begin{array}{c}\text { Frequency } \% \\
{[95 \% \text { IC }]}\end{array}$ & modal Class & Age $( \pm$ Sd $)$ & p \\
\hline Male & 590 & $42.1[39.5-44.6]$ & {$[60-70] 42 \%$} & $64.5( \pm 11.0)$ & \\
Female & 813 & $57.9[55.3-60.5]$ & {$[70-80] 37 \%$} & $68.2( \pm 11.3)$ & $<0.001$ \\
Total & 1403 & $\mathrm{H} / \mathrm{F}=1.01$ & {$[60-70] 37 \%$} & $66.3( \pm 11.6)$ & \\
\hline
\end{tabular}


Table 2. Age-based serology.

\begin{tabular}{ccccccc}
\hline Serology+ & $\mathbf{n}$ & $\begin{array}{c}\text { Prevalence } \% \\
{[95 \% \mathrm{IC}]}\end{array}$ & Age $( \pm \mathrm{SD})$ & Modal class & Serology- $( \pm \mathrm{SD})$ & $\mathbf{p}$ \\
\hline $\mathrm{HIV}$ & 65 & $4.6[3.7-5.9]$ & $71.9( \pm 9.5)$ & {$[60-70] 58 \%$} & $66.4( \pm 11.4)$ & 0.0016 \\
$\mathrm{HBV}$ & 40 & $2.9[2.1-3.9]$ & $73.7( \pm 14.5)$ & {$[60-70] 63 \%$} & $66.5( \pm 11.2)$ & 0.0154 \\
$\mathrm{HCV}$ & 165 & $11.8[10.2-13.6]$ & $83.5( \pm 6.1)$ & {$[80-90] 74 \%$} & $64.4( \pm 9.9)$ & $<0.001$ \\
Co-infections & 17 & $1.2[0.8-1.9]$ & $92.3( \pm 13.8)$ & {$[80-90] 41 \%$} & $66.4( \pm 9.9)$ & $<0.001$ \\
HIV/HBV & 2 & $0.14[0.04-0.52]$ & $79.0( \pm 0.0)$ & {$[70-80] 100 \%$} & $66.6( \pm 11.4)$ & 0.0555 \\
HIV/HCV & 8 & $0.57[0.29-1.12]$ & $90.6( \pm 7.0)$ & {$[90-100] 63 \%$} & $66.5( \pm 11.2)$ & $<0.001$ \\
HBV/HCV & 7 & $0.50[0.24-1.03]$ & $98.0( \pm 18.7)$ & {$[80-90] 57 \%$} & $66.5( \pm 11.1)$ & $<0.001$ \\
Total & 253 & $\mathbf{1 8}[16.1-20.1]$ & $\mathbf{7 8 . 4 ( \pm 9 . 3 )}$ & {$[80-90] 48 \%$} & $64.1( \pm 10.1)$ & $<0.001$ \\
\hline
\end{tabular}

HCV prevalence was $11.8 \%(95 \% \mathrm{CI}=[10.2-13.6])$ with mean age of $83.5 \pm$ 6.1 years compared to $64.4 \pm 9.9$ years for HCV seronegative people $\left(\mathrm{p}<10^{-3}\right)$. HCV seropositive modal age class was 80 - 90 years (74\%) (Table 2).

Co-infections affected $1.2 \%(95 \% \mathrm{CI}=[0.8-1.9])$ of the study population with mean age of $92.3 \pm 13.8$ years compared to $66.4 \pm 9.9$ years for non-co-infected participants $\left(\mathrm{p}<10^{-3}\right)$. Two patients were co-infected with HIV/HBV, 8 with HIV/HCV and 7 with HBV/HCV (Table 2).

\subsection{Viral Seroprevalence versus Gender}

Viral seroprevalence was observed for $20.8 \%$ of female and $14.2 \%$ of male ( $\mathrm{p}=$ $0.0015)$. HIV infection affected $5.5 \%$ of female versus $3.4 \%$ of male $(\mathrm{p}=0.0591)$. HBV infection affected $2.2 \%$ of female versus $3.4 \%$ of male $(\mathrm{p}=0.0924)$ and HCV affected $14.7 \%$ of female versus $7.6 \%$ of male $\left(\mathrm{p}<10^{-3}\right)$. Co-infections occurred in $1.7 \%$ of female and $0.5 \%$ male $(\mathrm{p}=0.0402)$ (Table 3$)$.

\section{Discussion}

This prospective study determined the prevalence of HIV, HBV, and HCV infections in the population of patients undergoing cataract surgery during a humanitarian mass surgical mission. Patients diagnosed with HBV and HCV not benefiting from additional tests to discern between cured and chronic hepatitis was one major limitation of this research. Risk factors of these 3 viral infections in the cataract-operated population not being investigated was another limitation.

\subsection{Prevalence}

An overall viral seroprevalence of $18.0 \%$ was measured regarding HIV, HCV and HBV transmissible infections. In two similar studies, assessed seroprevalence was three times lower than the present review, respectively $5.9 \%$ by Rewri and al [6] and $4.8 \%$ by Ambastha et al. [8].

In the present survey, $\mathrm{HCV}$ was the predominant transmissible viral infection and affected $11.8 \%$ of participants undergoing cataract surgery. A retrospective 
Table 3. Gender-based serology.

\begin{tabular}{ccccccc}
\hline Serology+ & $\mathbf{n}$ & $\mathbf{F}$ & $\mathbf{M}$ & $\mathbf{M} / \mathbf{F}$ & OR $^{*}$ & $\mathbf{p}$ \\
\hline HIV & 65 & $45(5.5 \%)$ & $20(3.4)$ & 0.44 & $1.67[0.97-2.86]$ & 0.0591 \\
HBV & 40 & $18(2.2 \%)$ & $22(3.4)$ & 1.22 & $0.58[0.31-1.10]$ & 0.0924 \\
HCV & 165 & $120(14.7 \%)$ & $45(7.6)$ & 0.38 & $2.09[1.46-3.00]$ & $<0.001$ \\
Co-infection & 17 & $14(1.7 \%)$ & $3(0.5)$ & 0.21 & $3.43[0.98-11.98]$ & 0.0402 \\
HIV/HBV & 2 & $2(0.2 \%)$ & 0 & 0 & $\mathrm{~N}$ & 0.1552 \\
HIV/HCV & 8 & $6(0.7 \%)$ & $2(0.3)$ & 0.33 & $2.19[0.44-10.87]$ & 0.3271 \\
HBV/HCV & 7 & $6(0.7)$ & $1(0.1)$ & 0.17 & $4.38[0.53-36.47]$ & 0.1357 \\
Total & 253 & $\mathbf{1 6 9 ( 2 0 . 8 )}$ & $\mathbf{8 4}(\mathbf{1 4 . 2 )}$ & $\mathbf{0 . 5}$ & $\mathbf{1 . 5 8}[1.19-2.10]$ & 0.0015 \\
\hline
\end{tabular}

Indian series of 560 cataract-treated patients estimated a lower prevalence of $0.53 \%$ [8]. Tahir et al. [9] and Rewri et al. [6] found respectively $6.17 \%$ and $4 \%$. HCV prevalence in the present series is identical to the Gabonese population prevalence of $11.2 \%$ [2.1 - 20.7] [15].

HIV seroprevalence came in second place of transmissible viral infections (4.6\%). The estimated HIV frequency among cataract operated participants was identical to the national prevalence [16]. However, observed values remain high compared to the data reported in the literature by Rawri et al. (0.09\%) [6] and Ambastha et al. (0.35\%) [8].

HBV was less common than the other two viruses, with a prevalence of $2.9 \%$. It is lower than the national prevalence of $8 \%$ [17]. However, it remains high compared other cataract surgery series [6] [8] [9].

Prevalence of co-infections (1.2\%) was very high in this survey. Two (2) patients had HIV/HBV combination and 8 others combined HIV/HCV. Only one case of HCV/HBV co-infection was recorded in a series of 4529 cataracts by Rewir et al. [6]. Other series with smaller numbers found no co-infection [6] [9].

\subsection{Age and Gender}

Viral seroprevalence was significantly higher among female. Profound feminization of transmissible viral infections may explain female predominance in the present study.

Viral infected patients were significantly older than non-infected. Co-infected ones were even older.

There are very few studies on viral infections in populations undergoing surgery. Gabon and the rest of Africa are faced with a huge burden of such infections, as confirmed by high seroprevalence among candidates for cataract surgery estimated in the present work. Asymptomatic viral infected patients provide a reservoir and the absence of routine screening prior to surgery is posing a serious a risk of transmission, especially in case of mass surgery programs. In cataract surgery, sharp micro-surgical instruments, handled under a microscope are ideal conditions for contaminating the nursing staff through accidental injuries. Risk of contamination between patients is possible from poorly sterilized 
soiled instruments. Cataract treatment, being a short surgical procedure, may lead to reduced sterilization time of instruments to maintain the turn-over of surgical interventions. This risk is even greater since studies have shown presence of these viruses in the ocular tissues [10] [11] [12]. More experimental studies have confirmed transmission risk during cataract surgery with phacoemulsification technique [13]. However, at this time, no known cases of transmission have been reported in the literature.

Virologic diagnosis of candidates for cataract surgery or any other surgery has a twofold interest: detecting thus treating early and preventing contamination. Screening for viral infections allows the medical staff to take extra precautions. Nevertheless, according to several authors this practice is of interest only in regions of high endemicity such as Gabon [18]. The downside is that it adds an extra cost to cataract surgery. However, this cost is reduced with the use of rapid detection tests with good sensitivity and specificity.

\section{Conclusion}

This study showed very high seroprevalence of HIV, HBV, and HCV infections among patients undergoing cataract surgery with predominance for HCV. Prevalence of viral co-infections was also significant. These results emphasize the need, in our context of high endemicity, to have HIV, HCV and HBV serologies as an integral part of the pre-operative assessment of cataract surgery.

\section{Conflicts of Interest}

The authors declare no conflicts of interest regarding the publication of this paper.

\section{References}

[1] Prévention de la cécité et des déficiences visuelles. https://www.who.int/blindness/causes/priority/fr/index1.html

[2] Perone, J.M., Lhuillier, L. and Zaidi, M. (2018) La chirurgie, seule stratégie thérapeutique de la cataracte. Acta Pharmaceutica, 57, 31-34.

https://doi.org/10.1016/j.actpha.2018.03.007

[3] Rapport mondial sur l'hépatite (2017). https://www.who.int/hepatitis/publications/global-hepatitis-report2017-executivesu $\underline{\mathrm{mmary} / \mathrm{fr} /}$

[4] VIH/SIDA. http://apps.who.int/mediacentre/factsheets/fs360/fr/index.html

[5] ONUSIDA - Lancement du rapport sur les données mondiales sur le sida. http://www.unaids.org/sites/default/files/media_asset/miles-to-go_en.pdf

[6] Rewri, P., Sharma, M., Vats, D.P. and Sighal, A. (2018) Seroprevalence, Risk Associations, and Cost Analysis of Screening for Viral Infections among Patients of Cataract Surgery. Indian Journal of Ophthalmology, 66, 394-399.

[7] Alhassan, M.B., Unung, P. and Adejor, G.O. (2013) HIV and HBsAg Seropositivity amongst Patients Presenting for Ocular Surgery at a Tertiary Eye Care Hospital in Nigeria. Open Ophthalmology Journal, 7, 18-19. https://doi.org/10.2174/1874364101307010018 
[8] Ambastha, A., Kusumesh, R. and Bhasker, G. (2016) Why Should Viral Markers Be Mandatory in Ocular Surgeries: A Hospital Based Retrospective Study. Journal of Clinical and Diagnostic Research, 10, LC9-LC11. https://doi.org/10.7860/JCDR/2016/21386.8713

[9] Tahir, M.A., Cheema, A. and Tareen, S. (2015) Frequency of Hepatitis-B and C in Patients Undergoing Cataract Surgery in a Tertiary Care Centre. Pakistan Journal of Medical Sciences, 31, 895-898.

[10] Temel, A., Seber, E. and Gunay, M. (1990) Detection of Hepatitis B Surface Antigen in Aqueous Humor. Acta Ophthalmologica, 68, 205-208. https://doi.org/10.1111/j.1755-3768.1990.tb01905.x

[11] Atas, M., Karatepe Hashas, A.S., Demircan, S., Sarıguzel, F.M., Baskan, B., Yuvac1, I., et al. (2016) The Investigation of HCV RNA in Tear Fluid and Aqueous Humor in Patients with Anti-HCV Antibody Positive Who Underwent Cataract Surgery. Ocular Immunology and Inflammation, 24, 297-301.

[12] Kashiwagi, K., Gohdo, T., Sato, S., Iijima, H. and Tsukahara, S. (2000) Detection of HIV-RNA in Aqueous Humor and Subretinal Fluid in an HIV Carrier with Rhegmatogenous Retinal Detachment. Japanese Journal of Ophthalmology, 44, 687-689. https://doi.org/10.1016/S0021-5155(00)00278-1

[13] Coelho, R.P., Garcia, T.V., Paula, J.S., Cruz, A.A., Rocha, E.M., Figueiredo, L.T., et al. (2012) Viral Contamination during Sequential Phacoemulsification Surgeries in an Experimental Model. Arquivos Brasileiros de Oftalmologia, 75, 174-177.

[14] Lien, T.X., Tien, N.T., Chanpong, G.F., Cuc, C.T., Yen, V.T., Soderquist, R., Laras, K. and Corwin, A. (2000) Evaluation of Rapid Diagnostic Tests for the Detection of Human Immunodeficiency Virus Types 1 and 2, Hepatitis B Surface Antigen, and Syphilis in ho Chi Minh City, Vietnam. The American Journal of Tropical Medicine and Hygiene, 62, 301-309. https://doi.org/10.4269/ajtmh.2000.62.301

[15] Gower, E., Estes, C., Blach, S., Razivi-Shearer, K. and Razavi, H. (2014) Global Epidemiology and Genotype Distribution of the Hepatitis C Virus Infection. Journal of Hepatology, 61, 45-57. https://doi.org/10.1016/j.jhep.2014.07.027

[16] Prévalence du VIH/sida au Gabon: Résultats de l’EDSG-II 2012. https://dhsprogram.com/pubs/pdf/HF44/HF44.pdf

[17] Hépatite, B. https://www.who.int/fr/news-room/fact-sheets/detail/hepatitis-b

[18] Ahmed, R. and Bhattacharya, S. (2013) Universal Screening versus Universal Precautions in the Context of Preoperative Screening for HIV, HBV, HCV in India. Indian Journal of Medical Microbiology, 31, 219-225.

https://doi.org/10.4103/0255-0857.115623 